\title{
A ATUAÇÃO DA DEFENSORIA PÚBLICA NO PROCESSO \\ PENAL EM PROL DO ACUSADO NÁO HIPOSSUFICIENTE E A JUSTA RETRIBUIÇÃO PELO SERVIÇO PÚBLICO PRESTADO
}

THE PERFORMANCE OF THE PUBLIC DEFENDER IN CRIMINAL PROCEDURE IN FAVOR OF THE NON-HYPOSSUFICIENT DEFENDANT AND THE FAIR RETURN BY THE PUBLIC SERVICE

PROVIDED

\begin{abstract}
Guillermo Rojas de Cerqueira César
Defensor Público Federal

Mestrando em Teoria do Direito e do Estado no Centro Universitário de Marília

(UNIVEM)

guillermo.rojas@dpu.def.br
\end{abstract}

\section{RESUMO}

A atuação da Defensoria Pública em prol do acusado não hipossuficiente no processo penal suscita várias dúvidas em relação a possibilidade de cobrança do serviço público prestado. A tese aqui desenvolvida revela que a previsão contida no atual código de processo penal náo contempla de forma adequada a nova roupagem constitucional em que a Defensoria está erigida. Não faz sentido desenvolver atividades atípicas da instituiçáo sem a possibilidade de previsão específica e cobrança pela justa retribuição do serviço público prestado. $\mathrm{O}$ constituinte reformador possibilitou a emancipação da instituição, cabendo a seus gestores a iniciativa e adequaçáo legislativa à nova realidade vivida.

Palavras-Chave: Defensoria Pública. Defesa Criminal. Hipossuficiência. Retribuição. Honorários. 


\begin{abstract}
The performance of the Public Defender's Office in favor of the the non-hypossuficient defendant in criminal proceedings raises several doubts regarding the possibility of charging for the public service rendered. The thesis developed here reveals that the prediction contained in the current criminal procedure code does not adequately contemplate the new constitutional guise in which the Public Defense is set up. It does not make sense to develop atypical activities of the institution without the possibility of specific prediction of their just retribution. The reforming constituent made possible the emancipation of the institution, and its managers had the initiative of legislative adaptation to the new reality lived.
\end{abstract}

Keywords: Public Defender. Criminal Defense. Hypossuficient. Retribution. Honoraria.

Data de submissão: 09/03/2018

Data de aceitação: 12/07/2019

\title{
SUMÁRIO
}

INTRODUÇÃO 1. A FUNÇÃO INSTITUCIONAL DE ATUAÇÃO DA DEFENSORIA PÚBLICA NO PROCESSO PENAL 2. EVOLUÇÃO LEGISLATIVA E JURISPRUDENCIAL: ADVOGADO DATIVO X DEFENSOR PÚBLICO 3.RETRIBUIÇÃO DO NÃO HIPOSSUFICIENTE PELO SERVIÇO PÚBLICO PRESTADO: QUEM DEVE COBRAR DO RÉU? 4. PROPOSTAS DE SUPERAÇÃO DO MODELO ATUAL. CONCLUSÓES. 


\section{INTRODUÇÃO}

A Defensoria Pública encontra lugar de relevo no contexto da Processualística do Direito Penal sendo este o locus por excelência do papel de resistência que desempenha dentre o rol de suas funçôes outorgadas pela Constituição Federal.

Certo é que com a edição das Emendas Constitucionais 74/2013 e 80/2014 pelo menos no "papel" a Defensoria Pública expandiu-se de forma a merecer, ainda que em tese, o mesmo tratamento outorgado às demais funçóes essenciais à justiça.

Em que pese o conteúdo formal do texto constitucional incumbir a Defensoria Pública da defesa dos direitos individuais e coletivos dos necessitados na forma do inciso LXXIV do artigo $5^{\circ}$ da Constituição Federal "O Estado prestará assistência jurídica integral e gratuita aos que comprovarem insuficiência de recursos" a temática continua a despertar intensas discussóes quando se trata da realização da defesa no âmbito do processo penal.

Isso porque, explica-se, o direito de defesa criminal é um direito irrenunciável e independente da condição financeira do acusado o Estado deve proporcionar ao cidadão meios aptos a garantia do contraditório e da ampla defesa, direitos fundamentais.

Em contraponto, nas demais searas do direito, como o direito civil e previdenciário, por exemplo, a não condição de hipossuficiência econômica afasta a Defensoria Pública do campo de atuaçáo, ensejando o indeferimento da assistência jurídica gratuita àqueles que não comprovarem insuficiência de recursos (econômicos/financeiros em grande parte dos casos).

Assim, exsurge o seguinte questionamento: A Defensoria Pública deve defender todas as pessoas no processo penal, ainda que tenham condiçóes de suportar o pagamento de advogados privados?

\section{A FUNÇÃo INSTITUCIONAL DE ATUAÇÃO DA DEFENSORIA PÚBLICA NO PROCESSO PENAL.}

Para responder a esse questionamento necessário se faz um maior aprofundamento sobre o tema.

A atuação na defesa criminal de réu que não contratou advogado, a depender de sua condição econômica pode ser classificada como função atípica da Defensoria Pública, muito bem conceituada por Roger Franklin Alves Silva e Diogo Esteves como sendo:

todas aquelas que não se relacionarem com a deficitária condiçáo econômica do sujeito, sendo desempenhadas pela Defensoria Pública independentemente da verificação de hipossuficiência do des- 
tinatário. Nesses casos, o fator econômico é irrelevante para que a Defensoria Pública possa exercer regularmente suas funçôes, bastando apenas que a hipótese legal de intervenção institucional esteja configurada. ${ }^{1}$

Merece relevo também a classificação cunhada por José Augusto Garcia de Sousa ${ }^{2}$ em que propóe a divisão das funçóes institucionais da Defensoria Pública alicerçando - se em funçóes tradicionais (ou "tendencialmente individualistas") e funçóes não tradicionais (ou "tendencialmente solidaristas"), abarcando as atribuiçóes que objetivam a proteção de valores relevantes do ordenamento jurídico, nesse segundo conceito, como a atuação de defesa do réu sem advogado na seara criminal e atuação da curadoria especial na esfera cível.

No mesmo sentido, de que a atuação no Processo Penal aos acusados que não contratem advogados para sua defesa, mesmo não sendo hipossuficientes financeiros, incumbiria a Defensoria Pública:

A nomeação ex officio pelo juiz do defensor público para atuar em uma determinada causa só pode se dar na hipótese de omissão/silêncio do réu. Tão importante e indisponível é a defesa técnica que pode ser exercida mesmo contra a vontade do réu, ou mesmo na sua ausência. Dessa forma, se o réu não constituir advogado, mesmo tendo recursos para tanto, a atuação do defensor público é obrigatória, já que a defesa técnica é indisponível no processo penal. Percebe-se, com facilidade, que no processo penal a atuação do defensor público não está vinculada à condição financeira de seu assistido ${ }^{3}$.

Assim, temos em primeira análise que constitui função institucional da Defensoria Pública atuar na defesa de réus no Processo Penal, independentemente de sua condição financeira, encontrando tal mister guarida na Lei Orgânica de regência da Defensoria Pública, notadamente no Art.4o da Lei Complementar 80/94.

\footnotetext{
1 ESTEVES, D.; SILVA, F. R. A. Princípios institucionais da Defensoria Pública. De acordo com a EC 74/2013 (Defensoria Pública da União), 2014, p.329.

2 SOUSA, J. A. G. de. O destino de Gaia e as funçôes constitucionais da Defensoria Pública: ainda faz sentido - sobretudo após a edição da Lei Complementar n. 132/09 - a visão individualista a respeito da instituição? In: SOUSA, J. A. G. de (org). Uma nova Defensoria Pública pede passagem: reflexóes sobre a Lei Complementar n. 132/90. Rio de Janeiro: Lumen Juris, 2011, p. 24.

3 CASARA, R. R. R; MELCHIOR, A. P. Teoria do Processo Penal Brasileiro, Dogmática e Crítica: Conceitos Fundamentais. Rio de Janeiro: Lumen Juris, 2013, p.426.
} 


\title{
2. EVOLUÇÃO LEGISLATIVA E JURISPRUDENCIAL: ADVOGADO DATIVO X DEFENSOR PÚBLICO
}

Além da previsão na Lei Orgânica Nacional da Defensoria Pública que dispõe sobre a atuação da instituição em favor do réu do processo penal que não tenha condiçóes de contratar advogado ou que não o faça, mesmo tendo condições, a previsão também está amparada no texto literal do Código de Processo Penal, elencando o artigo 263 a seguinte diretiva:

\begin{abstract}
Se o acusado não o tiver, ser-lhe-á nomeado defensor pelo juiz, ressalvado o seu direito de a todo tempo, nomear outro de sua confiança, ou a si mesmo defender-se, caso tenha habilitação.
\end{abstract}

Parágrafo único: $\mathrm{O}$ acusado que não for pobre, será obrigado a pagar os honorários do defensor dativo, arbitrados pelo juiz.

Contudo, a regra em comento deve ser analisada de forma consentânea ao momento histórico de sua promulgaçáo, eis que, fora elaborada quando do advento do Código Processual em 1941, época em que, salvo em alguns poucos estados da Federaçấo, a Defensoria Pública sequer existia.

Ao que parece, com a evolução Constitucional e com a afirmação do Direito Internacional dos Direitos Humanos a regra estampada acima somente poderá ser aplicada naquelas comarcas ou subseçóes judiciárias onde não houver Defensoria Pública instalada ou, mesmo instalada, não contar com número suficiente de defensores públicos.

Assim, "tendo sido citado pessoalmente o réu, e, nada obstante, não apresentado defesa, deve o juiz designar um defensor, dativo, onde não houver defensoria pública e for pobre o acusado, para a apresentação da resposta escrita”"

A afirmação dos processualistas merece reparo apenas no tocante ao termo pobre, haja vista que mesmo àqueles que possuam condições financeiras, em caso de não contratação de advogado após a citaçáo, será designado preferencialmente defensor público para atuação e apresentação de resposta escrita.

Inclusive, sustenta-se que a previsão atual do Código de Processo Penal enquadrar-se-ia em mais uma hipótese de norma "ainda" constitucional a exemplo daquela disposta no artigo 68 do mesmo diploma, trilhando o caminho para o reconhecimento de inconstitucionalidade quando da implantação e estruturação da Defensoria Pública em todas as comarcas e subseçôes judiciárias do pais, que aliás, deve ser completada em 08 (oito) anos, 2014, p. 540.

FISCHER, D.; PACELLI, E. Comentários ao Código de Processo Penal e sua jurisprudência, 
a teor do disposto no art. 98 do ADCT, acrescido pela EC 80/2014".

Nesse sentido, o Supremo Tribunal Federal já teve oportunidade de analisar a questão relativa ao Ministério Público, que em nosso sentir se aplica ao caso, analogicamente à relação advogado dativo x Defensoria Pública:

Ministério Público: legitimação para promoção, no juízo cível, do ressarcimento do dano resultante de crime, pobre o titular do direito à reparação: C. Pr. Pen., art. 68, ainda constitucional (cf. RE 135328): processo de inconstitucionalização das leis. 1. A alternativa radical da jurisdição constitucional ortodoxa entre a constitucionalidade plena e a declaração de inconstitucionalidade ou revogação por inconstitucionalidade da lei com fulminante eficácia ex tunc faz abstração da evidência de que a implementação de uma nova ordem constitucional náo é um fato instantâneo, mas um processo, no qual a possibilidade de realização da norma da Constituiçáo - ainda quando teoricamente não se cuide de preceito de eficácia limitada - subordina-se muitas vezes a alteraçóes da realidade fáctica que a viabilizem. 2. No contexto da Constituiçáo de 1988, a atribuiçáo anteriormente dada ao Ministério Público pelo art. $68 \mathrm{C}$. Pr. Penal - constituindo modalidade de assistência judiciária - deve reputar-se transferida para a Defensoria Pública: essa, porém, para esse fim, só se pode considerar existente, onde e quando organizada, de direito e de fato, nos moldes do art. 134 da própria Constituiçáo e da lei complementar por ela ordenada: até que na Uniáo ou em cada Estado considerado -, se implemente essa condiçáo de viabilizaçáo da cogitada transferência constitucional de atribuiçóes, o art. $68 \mathrm{C}$. Pr. Pen. será considerado ainda vigente: é o caso do Estado de Sáo Paulo, como decidiu o plenário no RE 135328. (STF RE 147776/SP - SÃO PAULO RECURSO EXTRAORDINÁRIO Relator(a): Min. SEPÚLVEDA PERTENCE Julgamento: 19/05/1998 Órgão Julgador: Primeira Turma Publicação DJ 19-06-1998 PP-00009 EMENT VOL-01915-01 PP-00136 Parte(s) RECTE.: ESTADO DE SÃO PAULO RECDO.: GERALDA CARDOSO DE PAULA)

Assim, podemos sustentar a seguinte conclusão: no contexto da Constituição de 1988 e nos termos do art. 98 do ADCT, a atribuição anteriormente conferida ao advogado dativo pelo art. 263 do Código de Processo Penal deve reputar-se transferida para a Defensoria Pública: essa, porém, para esse fim, só se pode considerar existente, onde e quando organizada, de direito e de fato, nos moldes do art. 134 da própria Constituição e da lei complementar por ela ordenada: até que - na União ou em cada Estado considerado -, se implemente essa condição de viabilização da cogitada transferência de atribuiçóes.

Art. 98. O número de defensores públicos na unidade jurisdicional será proporcional à efetiva demanda pelo serviço da Defensoria Pública e à respectiva população. $\$ 1^{\circ}$ No prazo de 8 (oito) anos, a União, os Estados e o Distrito Federal deveráo contar com defensores públicos em todas as unidades jurisdicionais, observado o disposto no caput deste artigo. $\$ 2^{\circ}$ Durante o decurso do prazo previsto no $\$ 1^{\circ}$ deste artigo, a lotação dos defensores públicos ocorrerá, prioritariamente, atendendo as regiōes com maiores índices de exclusão social e adensamento populacional. 


\section{RETRIBUIÇÃO DO NÃO HIPOSSUFICIENTE PELO SERVIÇO PÚBLICO PRESTADO: QUEM DEVE COBRAR DO RÉU?}

Caminhando na reflexão e superada a atuação da atividade defensória por advogados dativos questiona-se a possibilidade de cobrança pelo serviço prestado ao acusado em processo criminal que não seja hipossuficiente econômico.

A resposta tende a ser afirmativa, até porque a atuação em favor de réus que possuam condiçôes financeiras hígidas constitui atividade atípica da instituição Defensoria Pública e a alocaçáo de recursos humanos e materiais na defesa criminal de quem pode pagar pelo serviço pressupóe, em certa medida, menor tempo para a realização das atividades típicas.

Segundo Guilherme de Souza Nucci:

Dispóe a Constituição Federal que "o Estado prestará assistência jurídica integral e gratuita aos que comprovarem insuficiência de recursos" (art. 5., LXXIV), significando que o encargo não é geral, mas específico. Réus pobres têm o direito fundamental de obter defesa técnica gratuita nos processos criminais, mas aqueles que, favorecidos economicamente, náo desejando contratar advogado, por razóes variadas, obrigarem o juiz a nomear um defensor dativo ou mesmo um membro da Defensoria Pública, devem ser responsabilizados pelos honorários do profissional. Pode o Estado antecipar o pagamento do dativo, mas o ressarcimento há de ser exigido diretamente do acusado, em açáo à parte. Quanto aos defensores públicos, do mesmo modo, estáo eles obrigados a atuar em defesa daquele que não quer ser defendido, pois o direito é indisponível, mas o Estado cobrará os honorários devidos, igualmente. ${ }^{6}$

Ocorre, contudo, que a forma como se tem enfrentado a questão não parece ser consentânea ao arcabouço jurídico em que se sustenta a Defensoria Pública.

No âmbito da Defensoria Pública da União, o Conselho Superior regulamentou a temática por meio da Resoluçáo no 85/2014, normativa editada em 11 de fevereiro de 2014, portanto, anterior a promulgaçáo da EC no 80 de 04 de junho de 2014:

Art. $7^{\text {o }}$ Nos processos criminais, se restar constatado que a pessoa natural ou jurídica não é necessitada econômica, deverá o Defensor Público Federal provocar o juízo criminal para o arbitramento de honorários, os quais passam a constituir fonte de receita do Fundo de Aparelhamento e Capacitação Profissional da Defensoria Pública da União.

$\overline{6}$ NUCCI, G. de S. Código de processo penal comentado, 2014, págs. 624-625. 
A crítica lançada refere-se ao fato de que a solução encontrada repete a fórmula utilizada pelo legislador em 1941. Ora, se a defesa técnica é realizada por uma instituição autônoma administrativa e orçamentariamente e com iniciativa de lei e se o defendido possui condiçóes financeiras de arcar com o serviço prestado, nada mais natural e lógico que a própria instituição Defensoria Pública preveja qual o valor entenda correto pelo serviço prestado e cobre do assistido o valor devido.

Deixar o arbitramento de tão importante atividade nas mãos do Poder Judiciário levará, obrigatoriamente, que a instituição seja comparada, pelo menos nesse quesito, ao superado advogado dativo.

Ademais, esta fórmula de superação está prevista no Projeto de Lei do Novo Código de Processo Penal (PLS 156/2009):

Art. 59. A Defensoria Pública é instituição essencial à função jurisdicional do Estado, incumbindo-lhe a orientação jurídica e a defesa, em todos os graus, dos necessitados.

$\$ 1^{\circ}$ Com o fim de assegurar o contraditório e a ampla defesa no âmbito do processo penal, caberá à Defensoria Pública o patrocínio da defesa do acusado que, por qualquer motivo, não tenha constituído advogado, independentemente de sua situação econômica, ressalvado o direito de, a todo tempo, nomear outro de sua confiança, ou a si mesmo defender-se, caso tenha habilitação.

\section{$\$ 2^{\circ} \mathrm{O}$ acusado que possuir condição econômica e náo constituir advogado arcará com os honorários decorrentes da defesa técnica, cujos valores seráo revertidos à Defensoria Pública, nos termos da lei.}

Nota-se, que no projeto do novo Código, já não existe a previsão do advogado dativo, relegando a atividade de defesa técnica criminal exclusivamente à Defensoria Pública, pressupondo-se, com isso, a implantação definitiva da instituição a teor do disposto no art. 98 do ADCT.

Assim, a solução que se propóe, inclusive a ser estampada no Inciso XXI do art. $4^{\circ}$ da Lei Complementar no 80/1994 é no sentido de que compete a própria Defensoria Pública estabelecer os valores que serão devidos por sua atuação no âmbito da defesa criminal de assistidos que não sejam hipossuficientes.

Com a estipulação do valor e a cobrança do montante, estar-se-ia fortalecendo a um só tempo a atuação da instituição para aqueles a quem se destina e deixando de uma vez por todas de ser "soldado de reserva" junto ao poder judiciário.

A autonomia de uma instituição se faz também pela possibilidade de pactuar o valor de sua força de trabalho e cobrar pelo serviço público prestado daqueles que não sejam hipossuficientes econômicos. 
Mais uma vez estamos com Franklin Roger e Diogo Esteves para quem:

os órgãos de atuação e gestão interna da Defensoria Pública, por não possuírem existência autônoma ou vontade própria, não possuem capacidade processual para promover a execução dos honorários sucumbenciais devidos à Instituição. Com base na expressa redação do art. 40, XXI da LC ${ }^{\circ}$ 80/1994, acreditamos que a legitimidade ativa para a execuçáo dos honorários sucumbenciais deve ser outorgada, de maneira exclusiva, à própria Defensoria Pública, como instituição una e indivisível (art. $3^{\circ}$ da $\left.\mathrm{LC} \mathrm{n}^{\circ} 80 / 1994\right)^{7}$.

\section{PROPOSTAS DE SUPERAÇÁO DO MODELO ATUAL}

Superada a controvérsia e lançada a crítica relativa a adoção de modelo ultrapassado de retribuição ao serviço público prestado importa estabelecer parâmetros de compatibilização da lei ao novo modelo de Defensoria erigido através das recentes Emendas Constitucionais que deram nova roupagem à Defensoria Pública.

Entende-se que a cobrança pelo serviço prestado deve ter previsão legal, afastando no primeiro momento a possibilidade de os Conselhos Superiores das Defensorias regulamentarem a matéria através de resolução.

Isso porque, de acordo com Manuel Maria Diez, prestação "é uma atividade pessoal que um sujeito deve efetuar em benefício de outro sujeito a quem se proporciona uma utilidade concreta e em virtude de uma relação jurídica de natureza obrigatória entre as duas partes $^{8}$."

Esse tipo de prestação, que o exercício da defesa criminal revela, só pode ser tido em razão da utilização, efetiva, de serviço público específico e divisível, prestado ao contribuinte, caracterizado, portanto, como a figura tributária de taxa?

Somente após a previsão expressa em Lei Complementar poderia se cogitar a aplicação da regra do art. 10 , I, e art. 102 da Lei Complementar no $80 / 94$ pois não se trataria em um primeiro momento de exercício do poder normativo no âmbito da Defensoria Pública da

\footnotetext{
7 ESTEVES, D.; SILVA, F. R. A. Princípios institucionais da Defensoria Pública. De acordo com a EC no 74/2013 (Defensoria Pública da União), 2014, p.397.

8 DIEZ, M. M. Manual de Derecho Administrativo, 1980.

9 Art. 77. As taxas cobradas pela União, pelos Estados, pelo Distrito Federal ou pelos Municípios, no âmbito de suas respectivas atribuiçôes, têm como fato gerador o exercício regular do poder de polícia, ou a utilização, efetiva ou potencial, de serviço público específico e divisível, prestado ao contribuinte ou posto à sua disposição. Parágrafo único. A taxa não pode ter base de cálculo ou fato gerador idênticos aos que correspondam a imposto nem ser calculada em funçáo do capital das empresas. Art. 79. Os serviços públicos a que se refere o artigo 77 consideram-se: I - utilizados pelo contribuinte: a) efetivamente, quando por ele usufruídos a qualquer título; b) potencialmente, quando, sendo de utilizaçáo compulsória, sejam postos à sua disposição mediante atividade administrativa em efetivo funcionamento; II - específicos, quando possam ser destacados em unidades autônomas de intervenção, de unidade, ou de necessidades públicas; III - divisíveis, quando suscetíveis de utilização, separadamente, por parte de cada um dos seus usuários.
} 
Uniáo e nem atividade consultiva, normativa e decisória a serem previstas na lei estadual.

Trata-se efetivamente de obrigação imposta ao particular de valer-se do serviço público de defesa com amparo no art. $5^{\circ}$, inciso II, da Constituição Federal.

Aliás, esse caminho parece ter sido trilhado no supramencionado artigo 59 do projeto do novo código de processo penal eis que em seu segundo parágrafo dispóe expressamente que "o acusado que possuir condição econômica e não constituir advogado arcará com os honorários decorrentes da defesa técnica, cujos valores serão revertidos à Defensoria Pública, nos termos da lei" PLS 156/2009.

Assim, importa esclarecer de quem é a iniciativa de lei para prever a retribuição da função atípica prestada. Tal iniciativa deve ser analisada à partir da promulgaçấo da Emenda Constitucional 80 de 2014.

Convém destacar, contudo, como bem esclarece o Defensor Público Federal Caio Paiva:

que na redação original da PEC 247/2013 (Proposta que foi convertida na EC 80/14) se determinava somente a aplicação do artigo 93 da CF à Defensoria Pública, de modo que a instituição teria apenas a iniciativa de lei sobre o seu estatuto jurídico, tal como o STF tem a iniciativa de lei a respeito do Estatuto da magistratura. Foi apenas com a apresentaçáo (e aprovaçáo) de parecer redigido pela Comissão Especial constituída para analisar a PEC 243/2014 que um substituto se sobrepôs à proposta original, determinando, portanto, que também fosse aplicado à Defensoria Pública o artigo 96, II, já que, conforme anotou o relator, "as modificaçóes propostas [pelo projeto original], ainda que signifiquem notável avanço, não garantem à Defensoria Pública a iniciativa de lei naquilo que concerne diretamente à sua organização e funcionamento, como a criação e a extinção de seus cargos e dos serviços auxiliares ${ }^{10}$.

Resta evidente que a retribuição pelo serviço prestado, a ser destinado ao Fundo de Aparelhamento da instituição, concerne diretamente à organização e funcionamento da Defensoria Pública.

É pois, nesse contexto, que deve partir a leitura do artigo 93 "caput" da Constituição Federal, referenciado pelo art.134 $\$ 4^{\circ}$, muito bem explicado pelo Professor Daniel Sarmento para quem "a iniciativa legislativa para tratar de temas afetos à organizaçáo da Defensoria Pública é um requisito indispensável para assegurar a autonomia da instituição. ${ }^{11}$ ”

Prossegue o autor sustentando que:

10 PAIVA, C. A Defensoria Pública e a hipossuficiência jurídica no processo penal. Disponível em: <https://www.conjur.com.br/2015-fev-24/caio-paiva-defensoria-publica-hipossuficiencia-juridica>. Acesso em: 30 jun 2017.

11 SARMENTO, D. Parecer: Dimensóes Constitucionais da Defensoria Pública da União, 2015, p. 41. Disponível em: <http://www.anadef.org.br/images/Parecer_ANADEF_CERTO.pdf>. Acesso em: 10 jul de 2017. 
É verdade que o art. $61, \S 1^{\circ}$, inciso II, “d”, da Constituição, estabeleceu que são de iniciativa privativa do Presidente da República os projetos de lei relativos à "organização (...) da Defensoria Pública da União". Porém, tal dispositivo foi, nesta parte, tacitamente derrogado pela $\mathrm{EC}$ n $^{\circ}$ 80/2014, que acrescentou ao texto magno o art. $134, \$ 4^{\circ}$, determinando que se aplica à Defensoria, "no que couber, o disposto no art. 93 e no inciso II do art. 96 desta Constituiçáo". É que o art. 93, caput, da Constituição, atribuiu ao STF o poder de iniciativa de lei sobre o Estatuto da Magistratura. A aplicaçáo deste preceito em relaçáo à Defensoria implica o reconhecimento da iniciativa do Defensor Público-Geral Federal para leis que tratem da organizaçáo da DPU. Com efeito, ao atribuir a iniciativa do Estatuto da Magistratura ao STF, o claro propósito do constituinte foi reforçar a sua autonomia. Do mesmo modo, o espírito da EC no 80/2014, e a diretriz que se infere de todo o sistema constitucional, na sua atual configuraçáo, é o robustecimento da autonomia da Defensoria Pública, para que ela possa desempenhar eficientemente a sua missão constitucional, em prol dos direitos humanos dos necessitados. Não há qualquer singularidade da magistratura diante da Defensoria nesta matéria, que justifique a não aplicação do art. 93, caput, à última. Entendo que essa iniciativa é privativa do Defensor PúblicoGeral Federal, e não concorrente com a do Presidente da República, na mesma linha do que ocorre com o STF em relação ao Estatuto da Magistratura.

A EC no 80/2014 é superveniente ao art. 61, $\$ 1^{\circ}$, II, “d”, que já estava contido no texto originário da Carta. Aqui, é possível afirmar a revogação tácita da norma originária, em razão da sua incompatibilidade com a emenda constitucional posterior. Esta solução, ademais, prestigia mais a teleologia da Constituição, de fortalecer a autonomia da Defensoria, do que aquela que resultaria do reconhecimento da iniciativa concorrente do Presidente da República para leis sobre a organização da DPU, já que o exercício dessa suposta faculdade pelo Chefe do Executivo Federal poderia ameaçar a independência da instituição. Sem embargo, ainda que não se concorde com a tese mais ampla, da revogação tácita do art. $61, \$ 1$ º, II, "d”, da Constituição, não há como se objetar, no mínimo, ao reconhecimento do poder de iniciativa concorrente do Defensor Público-Geral Federal na matéria. A extensão do art. 93, caput, à Defensoria Pública também importa no reconhecimento do poder de iniciativa do Defensor Público-Geral Federal para a lei complementar que estabelece normas gerais para as defensorias públicas dos Estados e Distrito Federal. Trata-se da lei complementar referida no art. $134, \$ 1^{\circ}$, da Constituiçáo, que preceitua: " $\$ 11^{\circ}$. Lei Complementar organizará a Defensoria Pública da União e do Distrito Federal e dos Territórios e prescreverá normas gerais para a sua organização nos Estados, em cargos de carreira, providos na classe inicial, mediante concurso público de provas e títulos, assegurada a seus integrantes a garantia da inamovibilidade e vedado o exercício da advocacia fora das atribuiçóes institucionais." Muito embora o Defensor Público-Geral Federal não seja o chefe nacional 
da Defensoria Pública - cabendo-lhe apenas o comando da DPU -, a Constituição é clara ao aludir à existência de uma única lei complementar de âmbito nacional, que, simultaneamente, deve tratar da Defensoria Pública da União e estabelecer normas gerais para as defensorias dos Estados e do Distrito Federal. Discreparia a mais não poder o sistema constitucional atribuir aos defensores-gerais dos Estados o poder de iniciativa no âmbito do processo legislativo federal, que se desenvolve no Congresso Nacional. Em nenhum caso a Constituição Federal atribui a autoridades estaduais a prerrogativa de deflagrar o processo legislativo federal ordinário ou complementar ${ }^{12}$

Observe-se que o reconhecimento da iniciativa privativa ao Defensor Público Geral Federal na matéria é favorável aos interesses institucionais das próprias defensorias estaduais e distrital, considerando-se a alternativa de atribuí-la ao Presidente da República, que resultaria da aplicaçáo do art. 61, $\$ 1^{\circ}$, II, "d", CF - que, como visto, foi tacitamente derrogado pela EC no 80/2014. Afinal, o Defensor Público-Geral Federal não só detém maior expertise no assunto em questão - organização de defensorias públicas - , como também possui maior afinidade institucional em relação aos valores da Defensoria Pública do que o Chefe do Poder Executivo Federal. Assim, a solução que melhor corresponde ao texto e espírito da Constituição é a que atribui a iniciativa privativa de todas as matérias que devem ser contempladas na lei complementar referida no art. $134, \$ 1^{\circ}$, ao Defensor Público-Geral Federal - inclusive dos preceitos que consagrem normas gerais para a organização das defensorias nos Estados e Distrito Federal. ${ }^{13}$

Da análise mencionada pelo professor fluminense, podemos sustentar que a iniciativa de lei para prever a remuneração pelo serviço público prestado na defesa de réus não hipossuficientes é privativa, ou no mínimo concorrente, do Defensor Público Geral Federal, em razão da nova roupagem Constitucional erigida pelo advento da EC 80/2004.

Assim, caberá ao dirigente máximo da Defensoria Pública Federal a iniciativa para estabelecer as características de cobrança do tributo que gerará a contraprestação necessária ao serviço público prestado, nos termos do novo $\$ 4^{\circ}$ do art. 134 da Constituição, no qual remete a aplicação dos arts. 93 e 96 também à Defensoria Pública.

\section{CONCLUSÓES}

A regra estampada no art. 263 do Código de Processo Penal somente tem validade quando a defesa técnica for executada por Advogado dativo nomeado pelo juízo.

\footnotetext{
12 Em matéria de emendas à Constituição, existe a iniciativa de "mais da metade das Assembleias Legislativas das unidades da Federaçáo, manifestando-se, cada uma delas, pela maioria relativa dos seus membros" (art. 60, inciso III, CF).

13 Ibid. p.41-43.
} 
Defende-se a inconstitucionalidade progressiva da regra estampada no Código Processual, completando seu ciclo de validade com a materialização da norma contida no art. 98 do ADCT.

Nas comarcas e subseçóes judiciárias onde a Defensoria Pública estiver instalada competirá exclusivamente a ela o exercício da defesa criminal do réu que deixar de contratar advogado, mesmo não sendo hipossuficiente.

A atuação da Defensoria Pública nesses casos deverá ser justamente remunerada através de previsão específica na Lei Orgânica da instituição (Lei Complementar).

O projeto de lei relacionado ao novo Código de Processo Penal parece corroborar a tese aqui lançada eis que remete aos "termos da lei" a cobrança dos honorários decorrentes da defesa técnica exercida.

É do Defensor Público Geral Federal a competência exclusiva/concorrente para a iniciativa de lei que preveja a hipótese de cobrança dos honorários decorrentes da defesa técnica exercida aos acusados que possuírem condição econômica e não constituírem advogado.

À partir da alteração da Lei Complementar 80/94, com inclusão da hipótese de cobrança dos honorários decorrente da defesa técnica exercida aos acusados que possuírem condição econômica e não constituírem advogado, cada Conselho Superior poderá decidir qual a contraprestaçáo financeira adequada a remunerar a atuaçáo do órgáo de execução da Defensoria, através de tabela pré-fixada, por meio de resolução.

Sugere-se a seguinte redação ao novo Art. $4^{\circ}$, inciso XXI, da Lei Complementar 80/94 - executar e receber os honorários decorrentes da defesa técnica realizada em prol do acusado que possuir condição econômica e não constituir advogado, bem como as verbas sucumbenciais decorrentes de sua atuaçáo, inclusive quando devidas por quaisquer entes públicos, destinando-as a fundos geridos pela Defensoria Pública e destinados, exclusivamente, ao aparelhamento da Defensoria Pública e à capacitação profissional de seus membros e servidores;

Os valores revertidos a título de honorários deverão continuar a integrar o Fundo de Aparelhamento da Instituição, não tendo, sua percepção, caráter pessoal e sim institucional.

\section{REFERÊNCIAS}

BRASIL. Decreto-lei no 3.689, de 3 de outubro de 1941. . Projeto de Lei do Senado no 156 de 2009.

. Resoluçáo no 85 de 11 de fevereiro de 2014 do Conselho Superior da Defensoria Pública da União.

CASARA, R. R R; MELCHIOR, A. P. Teoria do Processo Penal Brasileiro - Vol.1, Dogmática e Crítica: Conceitos Fundamentais. Rio de Janeiro: Lumen Juris, 2013. 
DIEZ, M. M. Manual de Derecho Administrativo, tomo II. $1^{\text {a }}$ ed. Buenos Aires: Plus Ultra, 1980.

ESTEVES, D.; SILVA, F. R. A. Princípios institucionais da Defensoria Pública. De acordo com a EC 74/2013 (Defensoria Pública da União). Rio de janeiro GEN Editorial, 2014.

FISCHER, D.; PACELLI, E. Comentários ao Código de Processo Penal e sua jurisprudência. 6. ed. rev. e atual. - São Paulo: Atlas, 2014.

NUCCI, G. de S. Código de processo penal comentado. 13. ed. rev. e ampl. - Rio de Janeiro, Forense, 2014.

PAIVA, C. A Defensoria Pública e a hipossuficiência jurídica no processo penal. Disponível em: <https:/www.conjur.com.br/2015-fev-24/caio-paiva-defensoria-publica-hipossuficiencia-juridica>. Acesso em: 30 jun 2017.

SARMENTO, D. Parecer: Dimensóes Constitucionais da Defensoria Pública da União. Disponível em: <http://www.anadef.org.br/images/Parecer_ANADEF_CERTO.pdf>. Acesso em: 10 jul 2017.

SOUSA, J. A. G. de. O destino de Gaia e as funçóes constitucionais da Defensoria Pública: ainda faz sentido - sobretudo após a edição da Lei Complementar n. 132/09 - a visão individualista a respeito da instituiçáo? In: SOUSA, J. A. G. de (org). Uma nova Defensoria Pública pede passagem: reflexóes sobre a Lei Complementar n. 132/09.1 a ed. Rio de Janeiro: Lumen Juris, 2011. 